\title{
Development of Creative Abilities in Children Preschool and Younger School Age
}

\author{
Alexander Albertovich Mukhametshin ${ }^{1, *}$, Olga Borisovna Ushakova ${ }^{2}$, \\ Firdania Damirovna Mubarakshina ${ }^{3}$, Andrey Mikhailovich Siluyanichev ${ }^{3}$ \\ ${ }^{1}$ Department of Design and Public Arts, Institute of Philology and Intercultural Communication, Kazan Federal University, Tatarstan \\ ${ }^{2}$ Department of Architectural and Building Structures, Petersburg State University of Architecture and Engineering, Russia \\ ${ }^{3}$ Institute of Philology and Intercultural Communication, Kazan Federal University, Tatarstan
}

Received September 25, 2020; Revised November 23, 2020; Accepted December 4, 2020

\section{Cite This Paper in the following Citation Styles}

(a): [1] Alexander Albertovich Mukhametshin, Olga Borisovna Ushakova, Firdania Damirovna Mubarakshina, Andrey Mikhailovich Siluyanichev , "Development of Creative Abilities in Children Preschool and Younger School Age," Universal Journal of Educational Research, Vol. 8, No. 12A, pp. 7741 - 7747, 2020. DOI: 10.13189/ujer.2020.082561.

(b): Alexander Albertovich Mukhametshin, Olga Borisovna Ushakova, Firdania Damirovna Mubarakshina, Andrey Mikhailovich Siluyanichev (2020). Development of Creative Abilities in Children Preschool and Younger School Age. Universal Journal of Educational Research, 8(12A), 7741 - 7747. DOI: 10.13189/ujer.2020.082561.

Copyright $\odot 2020$ by authors, all rights reserved. Authors agree that this article remains permanently open access under the terms of the Creative Commons Attribution License 4.0 International License

\begin{abstract}
The article examines art education for children of preschool and primary school age as being the most effective tool for the formation of a full-fledged future personality. In modern preschool institutions and in elementary schools, art lessons are an integral part of the educational process, since the development of the creative abilities of the next generation from childhood is one of the top priority tasks of the domestic education system. Drawing is one of the children's most beloved activities. Children begin to draw before they can speak. While engaging in visual arts, they depict everything that they see; the more that they engage their imagination, the better their imagination and abstract thinking get, and their artistic taste is being formed. This article discusses the views of foreign and domestic experts - educators, psychologists, art historians and artists - on how children's personalities are successfully formed and developed in the process of artistic creation, and what accompanying conditions are needed. The current pedagogical experiment of the Children's Studio of Fine Arts and Design, in the Department of Design and National Arts of Kazan Federal University, was described; it is aimed at revealing the natural talents of children through teaching creativity. The results of the experiment will allow us to recommend the methodology of the Studio for use in schools, child care facilities, art studios, clubs, and art classes.
\end{abstract}

Keywords Art, Creativity, Elementary School Students, Preschoolers, Painting Techniques

\section{Introduction}

One of the main aims of our society is the upbringing of a comprehensively developed new generation. What will this future person be like? Obviously, they must have a versatile and multifaceted personality. On the one hand, we must nurture a person who is intelligent, emotionally and morally stable, patriotic, reliable, with noble human qualities. On the other hand, they must have flexible critical thinking and quick reactions to changing environmental circumstances and be able to act originally and to creatively solve complex problems [1].

The most significant part of a person's intellect is their creativity. Therefore, the development of the creative abilities of the younger generation is one of the most important tasks of the modern domestic pedagogy of education. We, as a people with a huge material and non-material cultural heritage, must understand that all this wealth is the result of the creative activity of several generations of our ancestors. Today, the preservation, development and enhancement of these values are possible only if our younger generation has the great 
creative potential [2].

The question arises: at what age should children be involved in activities aimed at developing creative abilities? The general opinion of teachers and psychologists is that the most favourable age for the development of children's creative abilities is the preschool and primary school age, from 5 to 10 years [3]. Experts in various scientific fields, who have conducted research on the problem, argue that introducing a child to creativity from their early years has several benefits. It leads to the accelerated development of their mental abilities, it better reveals their inherent natural potential, and it develops the logic of their thinking [4]; the internal evolution of the personality of children gets faster and more efficient. For the harmonious development of the personality of the child, it is best to introduce them to the world of beauty through visual activity. For the best manifestation of children's creative abilities, it is necessary to establish a creative environment in the classroom, a calm and friendly atmosphere, and to use classical and original techniques of visual and decorative art when teaching [5].

Modern realities are such that society requires not just people, but individuals whose creative abilities help them adapt to unfamiliar situations and make innovative decisions. The issue is very relevant, and the Uzbek education system is aimed at training such individuals.

A person who is able to creatively process information coming from the outside world has a high level of intellectual development. According to some researchers in the field of child psychology, the sensitive period for the development of human creative abilities is the age from birth to 6 years. It is very important to stimulate creative development precisely during this period - the role of this process in the formation of a comprehensively developed personality can hardly be overestimated: children learnability, mental processes develop, they are easily adapted to school, etc. [6].

Since 2017, important reforms in the field of education have been carried out in Uzbekistan, initiated by the President of the country Sh. Mirziyoyev. Thus, together with international experts from UNICEF, based on the experience of South Korea, the State requirements for the development of early and preschool children and the State curriculum of the Ilk Kadam DOE were approved, according to which each kindergarten has the right to develop its programs on the basis of Ilk Kadam and apply them in practice. In the context of the ongoing reforms, the issue of developing the creative abilities of the individual, as a subject of relations with the outside world, acquires special significance. That is why state requirements for the creative development of preschoolers suggest distribution in the following subdomains: the artistic vision of the world; artistic and creative abilities. What are your abilities? There are many scientific definitions of this concept. So, according to B. M. Teplov, abilities are "individual psychological characteristics that distinguish one person from another and are related to the success of any activity or many activities" [7].

KK Platonov interpreted abilities as "a part of the personality structure, which, being activated in a specific type of activity, determines the quality of the latter".

The famous psychologist N. S. Leites gave the following definition: "abilities are personality traits, on which the possibility of implementation and the degree of success of an activity depend" [8].

Doctor of Psychological Sciences L.A. Wenger believed that abilities are psychological qualities that are necessary for the performance of an activity and which manifest in it.

Summarizing the above, it can be concluded that abilities are understood as individual qualities of a person that provide a high degree of mastery of a certain activity. Speaking about creative abilities, as a rule, by most people this means abilities for artistic types of creative activity:

drawing, composing music, etc. But after all, an element of creativity can be present in any other kind of activity. Therefore, it should be remembered that the concept of "creative abilities" applies not only to artistic, creative abilities, but also to mathematical, and technical, and to all similar creative abilities. So, it can be said that "creative abilities" are the individual qualities of a person that are necessary for him to successfully carry out any creative activity [9]. The development of creative abilities means their unconditional improvement when a person reaches certain qualitative stages of development. At the same time, development takes place in two directions:

1. Spontaneous or deliberately uncontrolled, unplanned development.

2. Organized development, when a person consciously, purposefully develops his creative abilities [10].

Psychologist R.S. Nemov in his study guide on practical psychology argued that "any abilities not only manifest themselves but also develop in the form of activity that a person has taken up under the influence of the arisen interest." Nemov also divided the development into two areas: theoretical and practical. Both directions, the psychologist noted, are closely interconnected, because for the development of creative abilities, not only knowledge is needed, but also skills [11]. R. S. Nemov also determined the effective conditions for the development of the abilities of preschoolers:

1. The child must have certain inclinations.

2. These inclinations must be identified in a timely manner.

3. The child should be actively involved in the type of activity in which the corresponding abilities develop.

4. We need competent, trained teachers who are well versed in the development of appropriate abilities.

5. Modern, effective teaching aids are needed. Summing up the above, the conclusion suggests itself: in order to effectively use creative abilities, it is absolutely 
necessary not only to develop them, but to do it in the best conditions, as favourable conditions contribute to the complete assimilation of the necessary knowledge, skills, and help better fulfilment of certain tasks. Now let's talk about the physiological aspect of the sensitive period of development of creative abilities. Psychologists call different terms, but they all agree on one thing - you need to start developing creative abilities from a very early age when the brain of children is most plastic. Psychologists also note that, due to the curiosity of the child, characteristic of his age, the desire to know the world around him, preschool childhood is the most suitable time for the development of creative abilities and imagination.

Encouraging this kind of cognitive activity, parents should share their knowledge with children involving them in different types of activities. The child's experience and stock of knowledge is the most important prerequisite for future creative activity because their thinking is still free from the dogmas and stereotypes of life that an adult [12]. But it should be remembered that the opportunities for the development of abilities do not remain stable when they reach a maximum at the time of "maturing" - the less often they are used, the faster they degrade.

Thus, it becomes obvious that preschool age is a time of excellent opportunities for the development of creative abilities, and the adult's creative potential depends on how these abilities were used in his childhood. Despite the different points of view of researchers on the question of what creative abilities are, of which components they form, all authors unanimously note creative imagination and the quality of creative thinking, considering these two concepts to be essential components of creative abilities [13].

\section{Materials and Methods}

In the world of pedagogical science and practice, much attention has been paid to the development of children's abilities through artistic creation. The work of S.V. Kuzhevatova outlines the views of foreign researchers on children's visual art. She writes that children's visual art began to draw the special attention of teachers, psychologists, and art historians at the end of the 19th century. This was due to the rapid development of science and culture, as well as the formation of a new direction in psychology - child psychology. Specialists of that period often used drawings as an object of investigation for examining the psychology of a child. In studies written at the turn of the 20th century, the originality of children's drawings was considered as a naive reflection of reality [14].

More progressive ideas in understanding the of the child creativity were formed in the second half of the twentieth century. After the Second World War, international organizations were created to tackle the issues of raising and educating children. Psychologists say that all children are talented and that in their drawings, each child reveals an individuality. Through introducing the child to various types of artistic activity, one can direct his/her aesthetic development (Karlavaris). Some experts believe that art contributes to cultural development and personality formation, acting on children as art therapy [15].

A number of scientists argue that it is important to study not the result but the process of the child's creative activity: their actions and emotions. Creativity affects a person throughout life, and scientists consider early childhood the most sensitive period.

The consideration of children's drawing as an activity independent of external circumstances led to the idea of the existence of a unified evolution of creativity for all eras and peoples. Three periods of development were identified: 1st period - pre-figurative (doodling); 2nd period - a period of schematic images of symbolic nature; 3rd period - transition to a true, realistic image [16].

Children's visual art is considered by a number of foreign experts not only as a means of developing children's creativity but also as a means of treating the soul: art therapy, which is so necessary for the fragile psyche of a child. In the process of artistic creation, a child exists in his/her own special world, which gives him/her joy, positive emotions, favourably affects the nervous system and instils self-confidence [17].

The development of children's visual art and the specifics of working with children in different childhood periods of preschool and primary school were considered in the studies of domestic specialists: art historians A.V. Bakushinsky, teachers G.V. Labunskaya, E.A. Flerina, N.P. Sakulina, T.S. Komarova, T.G. Kazakova; psychologists E.L. Ignatiev, V.I. Kirienko, V.S. Mukhina, O.M. Dyachenko. The humanistic orientation of the work of our scientists is obvious; it is aimed at the development and enrichment of the concept of children's art, conceived as an activity close to the children's nature, with their immediacy, emotions, and joys. However, despite the great interest of psychologists, educators, artists and art historians in the issue, children's creativity has not been considered systematically enough. Therefore, today a comprehensive study of the problems of facilitating children's visual art is very relevant [18].

\section{Results and Discussion}

In preschool and in elementary school, visual arts are an important part of the educational process. In general, drawing is one of the most accessible and most absorbing types of children's art. Children learn to draw and fall in love with it from a very young age. Even those children who do not have artistic abilities show an early interest in the drawing: they are ready to paint every day, while 
unconsciously trying to improve their drawing skills. In the process of drawing, children not only depict everything they see but also actively show their own imagination, while their abstract thinking and spatial awareness develop [19].

In the process of artistic creation, children's mental abilities are formed, memory is trained, and the fine motor skills of the hands are developed. While in the interesting creative process of painting, children unconsciously learn to think, comprehend, compare, and combine the depicted objects and surrounding objects, which ultimately develop their ability to analyze, imagine and fantasize [20].

It is difficult for a small child to depict objects, animals, the environment in the correct way, and to choose themes for drawing by themselves; they do not know the whole variety of techniques and tools for drawing. In such a situation, we can hardly expect variety in children's drawing. Therefore, young children are very fond of colouring books, which are now selling in large numbers on a wide variety of topics. Since children do not have the skills to depict the objects of their surrounding reality, the use of ready-made pictures allows them to create the illusion of drawing "for real" in their minds; this certainly has a positive effect on self-esteem and encourages children to continue their passion for drawing [21].

As a rule, it is difficult to classify children's works by their technique or genre: most often they draw "anything and everything", using at the same time many tools at once: coloured pencils, paints, felt-tip pens, and crayons, etc. Therefore, at the initial stage, it is very important to organize the drawing process in a systematic manner, guiding the children's interest in visual arts in the right direction [22].

For the second year running, a creative laboratory, the Children's Studio of Fine Arts and Design, has been working at the Kazan Federal University in the Department of Design and National Arts. The main contingent of students in the studio is preschoolers and primary school students, aged from 5 to 10 years. The team of the Department of Design and National Arts has conducted a pedagogical experiment in the studio aimed at identifying the creative abilities of children through training in artistic creation, applied art, foreign languages, and music; teachers try to stimulate children to learn. Artists, designers, architects and lecturers of the department rely on practical, worldly experience, and their scientific research [23],[24]. The analysis of the first results of the pedagogical experiment showed that in the process of learning, students acquire not only drawing skills, but also the ability to represent the environment in an imaginative way, learn non-standard approaches to solving not only creative tasks, but also real-life situations. At the heart of the creative process of teaching children in the studio are drawing, painting, and arts and crafts [25].

Drawing is one of the most popular types of visual activity and creativity. Drawing is a technique for creating all kinds of images on various surfaces. Drawing for the child serves as a means of understanding the world and reproducing it. Painting is another popular kind of visual art, a way of capturing the world around us with paints on the surface of a sheet of paper, objects, or walls. The main expressive means in painting is

colour, which affects the viewer's general perception of the picture, making them pay attention to important details and enhancing the emotional component of the work. Decorative and applied art is a type of artistic creativity aimed at creating products that combine artistic and utilitarian functions, and folk art is the basis and source of it. In working with children, it is important to try out every kind of visual art, since they all contribute to their development not only in the creative environment but also in general. The studio uses a wide variety of visual techniques. The limited scope of this article, unfortunately, does not make it possible to get acquainted with all of them, but we can still consider some [26].

Painting with stamps. Materials: plasticine, die base, cutter, sponge, paints. A stamp easily can be made from plasticine. Plasticine is applied to a bar, cube, etc. With a sharp object, we apply an image or an abstract pattern, and the stamp is ready. From the sponge, we make something like a stamp pad and pour paint on it. We apply the stamp to the sponge with paint and then make prints.

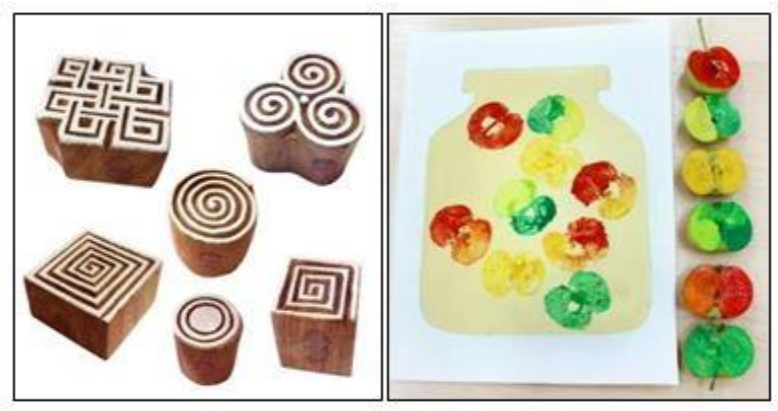

Figure 1. Painting with stamps

Stamps made of cups or bottlenecks. Materials: paper, gouache paints, plastic cups and bottles with necks of different sizes, flat plate. We pour the paint onto a plate. We dip the cup in the paint and print it on a sheet of paper. We do the same with bottlenecks. Themes of drawings and compositions can be very diverse.

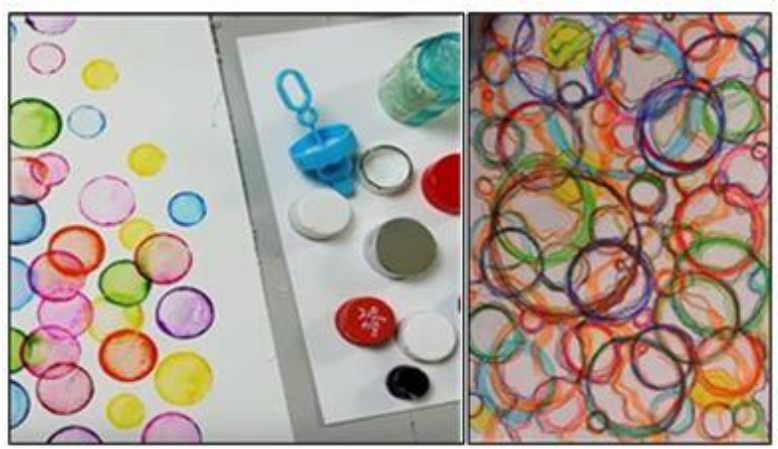

Figure 2. Print-making with cup prints or bottlenecks 
Crumpled image. Materials: paper, gouache paints, brushes, wax crayons, sponge. An object is drawn with wax crayons on paper; around it, the whole space is also coloured over with crayons. Now we gently mash this sheet, then straighten it and cover it with gouache. Then we quickly wash off the gouache with a sponge and dry the work. The paint should remain only in the places where the paper was folded.

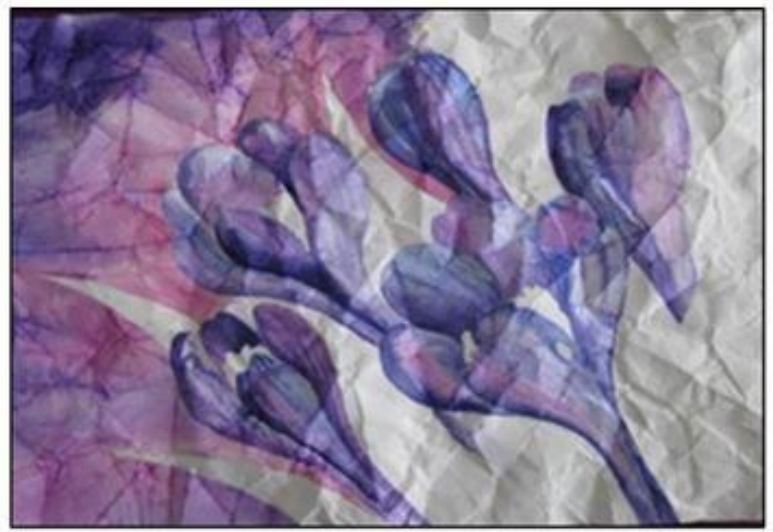

Figure 3. Pattern on crumpled paper

To get the image, we need to drip and let the paint spread on the sheet. Blots can be blown into the center through a tube. Images from blots can be mirrored if we first fold the sheet in half, then flatten it and drip on it with paint. Now we fold the sheet again and gently press it. Next is a matter of imagination. We need to consider the blots, identify what they look like, and finish the details.

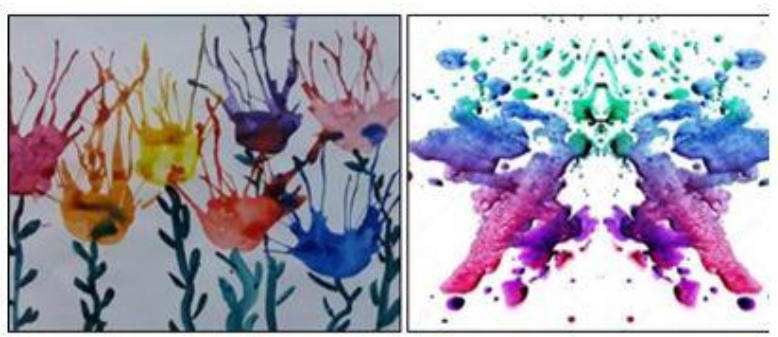

Figure 4. Paintings with a blotting technique

Griffonage (scribble). Materials: paper, pencil, watercolour, felt-tip pen, brush. In drawing using the 'griffon' technique, it is impossible to predict what will be the result: it all depends on randomly drawn lines and the author's imagination. For this unconventional technique, a single continuous line is made on the paper with a graphite pencil. The line can bend and break in different directions. Then it is necessary to consider the resulting lines and activate the imagination to find the contours of animals, fish, plants, etc. in the scribbles; then we select the silhouettes and contours of objects with a felt-tip pen and paint them to obtain a complete image.

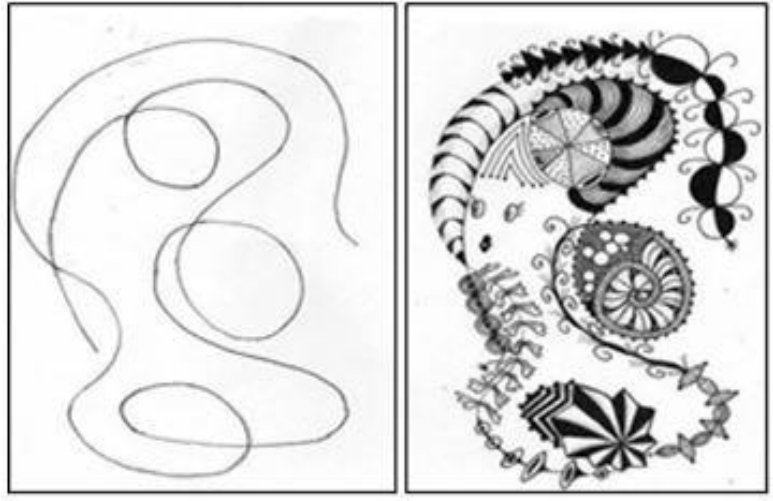

Figure 5. Stages of the Griffonage technique

Volumetric painting. Materials: PVA glue, shaving foam, gouache, mixing bowl, brushes, paper. This technique is designed to create puffy patterns. Such paint is made at home quickly and simply: PVA glue, gouache and shaving foam are mixed in a bowl. Children will definitely appreciate such an experiment and, of course, the amazing colours of the final result.

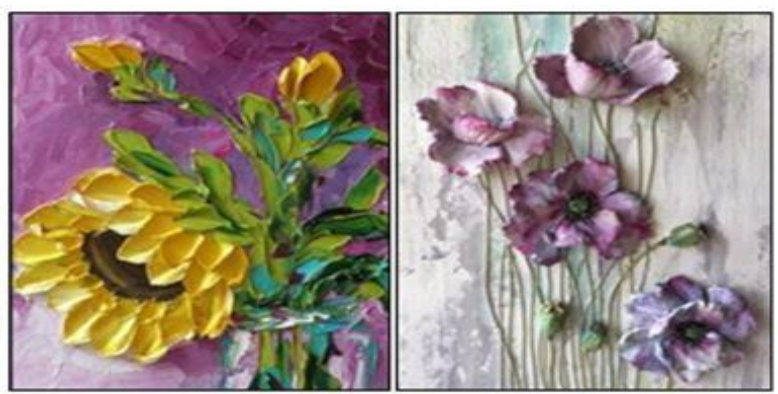

Figure 6. Volumetric painting

Pointillism: drawing with dots. Materials: paper, paints: watercolour or gouache, cotton buds/brushes, and felt-tip pens can be used. A feature of this technique is drawing with dots and strokes, avoiding mixing paints on the palette. Spatial colour mixing is obtained if you look from a certain distance at the small, coloured spots touching each other. The fusion of colours from a distance is explained by light scattering and structural features of the human eye, all occurring according to the rules of optical illusions.

Scratching. Materials: cardboard, oil pastel, gouache, toothpick, brush. Before starting work, it is necessary to prepare cardboard. It must be covered with a thick layer of wax or multi-coloured oil pastels. Then with a wire brush or sponge, you need to apply a layer of dark paint onto the cardboard surface. When the paint dries, we scratch it with a sharp object (toothpick, knitting needle). Thin monotone or multi-coloured strokes appear on a dark background, building up a picture. 


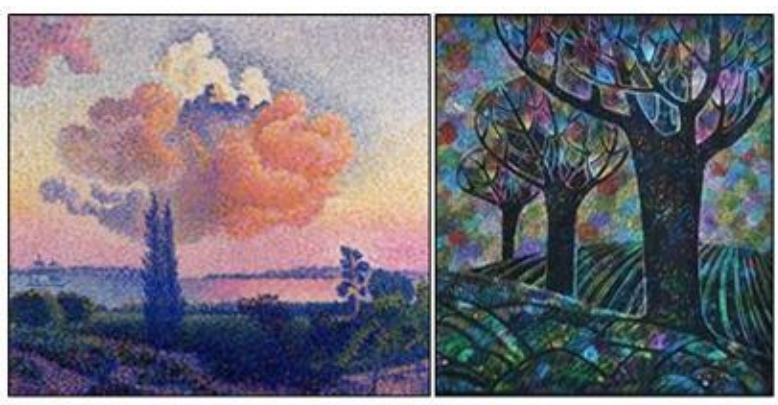

Figure 7. Work in the style of "pointillism."

\section{Conclusions}

The successfully conducted experiment and its results allow us to recommend the obtained teaching methodology for use both in ordinary schools and institutions, and in children's art studios, clubs, and art classes. In fact, children's creativity is limitless, just like their imagination. When they engage their creativity, it develops, along with their thinking and artistic abilities. This must be understood and supported. At the Children's Studio of Fine Arts and Design of KFU, the teachers who work with the children are always open to experimentation and new painting techniques. They, being professionals, understand how important it is to be able to interest a child, to draw their attention towards creativity and art. Children, in turn, really like to discover and understand themselves in the creative process.

From the point of view of psychology, art is a process through which something new is created, and a system of personality traits, thanks to which a person is involved in this process. Philosophy interprets artistic creation as generating something new human activity, due to which, on the basis of objective laws of reality, the natural and social world changes based on the artistic needs of mankind.

From any point of view, creativity is a creative process of transforming the old into the new. Can artistic work be called full-fledged if a person has a great idea? No, this is not enough; the idea that has arisen must be embodied in reality, it must become a public domain available for acceptance by other people. Yes, artistic creativity is part of his personality, but in order to reveal this part, suitable conditions are required.

Summing up, if you do not take into account the final result, then it is almost impossible to understand the essence of the process of artistic creation because there are various forms of completeness of perfection. Nevertheless, artistic creativity has its own defining characteristics:

New artistic values are created; Various, seemingly in appearance, combinations are combined; The creative potential of a person is realized. Of course, the creative energy of a person should be directed towards the development of society.

Therefore, it is very important to instil in a child the value of world culture, as well as the culture of his people. The child must learn to strive for excellence and realize his ideas, bringing them to an end.

Thus, artistic creativity is nothing more than the highest form of self-expression of a person's mental activity, aimed at creating new ones both in design and in the form of aesthetic values, as well as the realization of a person's creative forces and abilities.

\section{Acknowledgements}

The work is performed according to the Russian Government Program of Competitive Growth of Kazan Federal University.

\section{REFERENCES}

[1] Imber-Black, E. (2005). Training for a new generation. Family Process, 44(3), 245-253.

[2] Dere, Z. (2019). Investigating the Creativity of Children in Early Childhood Education Institutions. Universal Journal of Educational Research, 7(3), 652-658.

[3] Solovyova, N.N., \& Sidorova, K.A. (2020). Development of schoolchildren's creative abilities. Kazan University Press, 231- 236 .

[4] Akhmetshina, E. G., \& Kadyjrova, L. H. (2017). Pedagogical approaches to the development system of the artistic culture of individual. Revista san gregorio, (20), 188-193.

[5] Kharchenko, N. V. (2017). Language personality of a preschool child: features of development in the process of listening. Psycholinguistics, (21 (1)), 171-185.

[6] Sharipov, S. (2020). Professional Trainig Development as A Main Aspect Of Pupil'S Creative Abilities Development. Архив Научных Публикаций Jsp (In Russia).

[7] Khamidovich, T. N., Nozimovich, T. N., Ibrohimovna, Y. N., Ravshanovich, J. R., \& Kholmuratovich, M. K. (2020). DEVELOPMENT OF STUDENTS'CREATIVE ABILITIE $S$ THROUGH TEACHING. Journal of Critical Reviews, 7(6), 227-230.

[8] Platonov K.K. The structure and development of personality. M., 1986.

[9] Shcherbakov, V. S., Makarov, A. L., Buldakova, N. V., Butenko, T. Y. P., Fedorova, L. V., Galoyan, A. R., \& Kryukova, N. I. (2017). Development of higher education students' creative abilities in learning and research activity. Eurasian Journal of Analytical Chemistry, 12(5), 765-778.

[10] Fedorchuk, H. M. DEVELOPMENT CREATIVE ABILITIES YOUNGERS SCHOOLBOYS THE LESSONS LABOR TRAINING. 
[11] Miçoogullari, B. O., \& Ekmekçi, R. (2017). Evaluation of a Psychological Skill Training Program on Mental Toughness and Psychological Wellbeing for Professional Soccer Players. Universal Journal of Educational Research, 5(12), 2312-2319.

[12] Vasilieva, E. V. (2018). Developing the creative abilities and competencies of future digital professionals. Automatic documentation and mathematical linguistics, 52(5), 248-256.

[13] Nozimovich, T. N., Ibrahimovna, Y. N., \& Ravshanovich, J. R. (2020). Development Of Student's Creative Abilities In The Fine Arts In The Higher Education System. The American Journal of Social Science and Education Innovations, 2(07), 232-238.

[14] Kuzhevatova, S.V. (2020). The views of foreign researchers on the problem of children's fine art" - URL: https://solncesvet.ru/opublikovannyie-materialyi/vzglyadyzarubejnyh-issledovateley-na-pr422748/ (accessed: 05.22.2020)

[15] Thompson, G. (2014). Process and product: The art of Edith Kramer. Art Therapy, 31(4), 183-190.”

[16] Akkanat, Ç., \& Gökdere, M. (2018). The Effect of Academic Involvement and School Climate as Perceived by Gifted Students in Terms of Talent, Creativity, and Motivation in Science. Universal Journal of Educational Research, 6(6), 1167-1174

[17] . Chou, P. N., Chang, C. C., \& Chen, M. Y. (2017). Let's Draw: Utilizing Interactive White Board to Support Kindergarten Children's Visual Art Learning Practice. Journal of Educational Technology \& Society, 20(4), 89-101.
[18] Stojanović-Stošić, M. (2017). Development of children's creative abilities in arts education by applying tactile, visual and auditory stimuli. Godišnjak Pedagoškog fakulteta $u$ Vranju, 8(2), 311-324.

[19] Jenson, K. (2018). Early childhood: Learning through visual art. He Kupu the Word, 5(3), 75-82.

[20] DOLĞUN, Ö. B. A View To Philosophy On The Process Of Artistic Creation.

[21] Lev-Wiesel, R., Hazan, M., Daniel, M., German, V., Finger, Z., Weinger, S., \& Binson, B. (2020). Children Drawing Violence: To What Extent Does It Reflect Actual Experience. The Arts in Psychotherapy, 101717.

[22] Suvonova, K. (2020). Factors of interest of children to art in artistic activity. International Journal on Integrated Education, 3(5), 1-3.

[23] Musina, K.M., \& Akhmetshina, E.G. (2020). The development of the artistic culture of schoolchildren in the process of studying cultural heritage in creative classes. Kazan: "Kazan University Press", 206-210.

[24] Akhmetshina, E. G., \& Kadyjrova, L. H. (2017). Pedagogical approaches to the development system of artistic culture of individual. Revista san gregorio, (20), 188-193.

[25] Cremin, T., \& Barnes, J. (2018). Creativity and creative teaching and learning.

[26] De Pisapia, N., Bacci, F., Parrott, D., \& Melcher, D. (2016). Brain networks for visual creativity: a functional connectivity study of planning a visual artwork. Scientific reports, 6, 39185 . 